REVIEW

\title{
REVIEW OF MATERNAL MORTALITY IN ETHIOPIA: A STORY OF THE PAST 30 YEARS
}

\author{
Yifru Berhan ${ }^{1}$, Asres Berhan ${ }^{2}$
}

\begin{abstract}
BACKGROUND: Ethiopia is one of the six countries which have contributed to more than $50 \%$ of all maternal deaths across the world. This country has adopted the millennium development goals (MDGs) including reducing the maternal mortality by three-quarter, and put improvement in maternal health as one of the health sector development program (HSDP) performance indicators. The purpose of this study was to review the maternal mortality ratio (MMR) in Ethiopia in the past 30 years using available literature.

METHODS: A computer based literature search in the databases of MEDLINE, PubMed, HINARI, EBASE, MEASURE DHS, The Cochrane Library, Google Search and Google Scholar was carried out. Manual search for local articles that are not available electronically in full document were also conducted. Eighteen data sources (3 nationally representative surveys, 2 secondary data analyses, 5 small scale community based studies, and 8 hospital based studies) were included in the review. The results of this review are presented in the form of line and stock graphs.

RESULTS: The national maternal mortality trend estimated by the central statistics agency of Ethiopia, The Institute for Health Metrics and Evaluation, WHO and other UN agencies showed inconsistent results. Similarly, although there were marked variations in the 95\% confidence intervals among individual studies, the small scale community based and hospital based studies have shown that there has been no significant change in maternal mortality over the last three decades. A 22-year cohort analysis from Atat Hospital is the only evidence that demonstrated a very significant drop in maternal mortality among mothers who were kept in the maternity waiting area before the onset of labor.

CONCLUSION: Although the MDG and HSDP envisaged significant improvement in maternal health by this time, this review has shown that the performances are still far from the target. The multisectoral huge investment by the Ethiopian Government is a big hope to reduce the maternal mortality by threequarters in the near future beyond 2015.

KEYWORDS: community and hospital based, Ethiopia, maternal mortality ratio, trend
\end{abstract}

DOI: http://dx.doi.org/10.4314/ejhs.v24i1.2S

\section{INTRODUCTION}

Globally, pregnancy related complications account for five million maternal deaths (1). According to Hogan et al (2), the global estimate of maternal mortality ratio (MMR) decreased from 422 (95\%CI: 358-505) in 1980 to 251 (95\% CI: 221289) per 100,000 live births in 2008. After two years, the World Health estimate for 2010, however, was more than double of the estimate made by Hogan et al (521/100,000 live births) (3). The World Health Statistics 2013 also showed that the MMR in some high income countries ranges from 3-5/100,000 live births. As a result, the mean MMRs of countries with low income, lower middle income, upper middle income and high income groups were 410, 260, 53, and 14/100,000 live births, respectively.

\footnotetext{
${ }^{1}$ Hawassa University, College of Medicine and Health Sciences, Department of Gynecology-Obstetrics

${ }^{2}$ Hawassa University, College of Medicine and Health Sciences, Department of Pharmacology

Corresponding Author: Yifru Berhan, Email: yifrub@yahoo.com
} 
It was also reported that more than $50 \%$ of all maternal deaths worldwide occurred in three Asian (India, Pakistan, Afghanistan) and three African (Nigeria, Ethiopia, and the Democratic Republic of Congo) countries $(2,4)$. It was also noted that four low income Asian countries (Nepal, North Korea, Kyrgyzstan, and Tajikistan) were able to reduce the MMR to 65-200 per 100,000 live births (3).

The international community declared its commitment several times to reduce maternal and neonatal mortality in low income countries like Ethiopia. The 1987 Safe Motherhood Conference in Nairobi, followed by the 1990 World Summit at UN headquarters, the 1994 International Conference on Population and Development in in Cairo, the 1995 Fourth World Conference on Women in Beijing, 'Nairobi 10 years on' in Sri Lanka in 1997, and the Millennium Development Goals (MDGs) established by the UN in 2000 were at the forefront (5).

Ethiopia, as UN member country that signed several international agreements, has adopted the MDGs. Among others, MDG5 (reduction of maternal mortality by three-quarters between 1990 and 2015) has got special consideration by the Ethiopian Government and its partners. As a complimentary, the Federal Ministry of Health of Ethiopia has developed several working documents to achieve MDG 5. Among others, the 20-year rolling Health Sector Development program (HSDP) formulated in 1998, which has reached its fourth stage (HSDP IV), and the Ethiopian National Reproductive Health Strategy in the years 2006-2015 gave emphasis to maternal health. Decreasing the MMR to 267/100,000 live births is one of the HSDP IV performance indicators $(6,7)$.

MDG 5 is intended to be achieved through raising the proportion of fetal births attended by skilled health personnel and upgrading the status of women through education and enhancing their participation in the work force. As one of the strategies to reach the community at large, the Health Extension Program (HEP) was launched in 2003 and is being implemented since 2005 (8). Reducing the maternal mortality through the provision of family planning at the lowest level (household, health post) and providing clean and safe delivery at home and in the health posts are among the objectives of the HEP.
To know how far from or how close we are to the set target (MDG 5 and HSDP IV), the national MMR of Ethiopia was estimated by the Ethiopian Demographic and Health Surveys (EDHS 2000, 2005 and 2011) (9-11), WHO (World Health Statistics 2013) (3) and the Institute of Health Metrics and Evaluation (IHME) at the University of Washington in the USA (2).

Unlike previous reviews $(12,13)$, which included only local data before 2008 , this review includes all national MMR estimates (2, 3, 9-11) with $95 \%$ confidence intervals. All hospital based and small scale community based studies reported between 1977 and 2012 are also included. Additionally, the Ethiopian MMR trend is compared with that of Sub Sharan African countries (SSA) grouped in four zones. Thus, the purpose of this study was to review the MMR in Ethiopia during the past 30 years period using available literature from national surveys, community based and hospital based small scale studies, and national estimates by WHO and IHME.

\section{METHODS}

In this assessment, a literature review was carried out first by conducting a computer based literature search in the databases of MEDLINE, PubMed, HINARI, EBASE, and The Cochrane Library. The electronic based literature search was strengthened by using the Google Search and Google Scholar search engines. The search was further supplemented by searching the reference lists of each retrieved article.

During the literature search, the following search terms were used in an alternate combination by both authors (YB and $\mathrm{AB}$ ) with the help of the Boolean logic (AND, OR and NOT): millennium development goals (MDGs), Ethiopia, maternal health, maternal morbidity, maternal mortality. The website of MEASURE DHS was also searched for the final reports of demographic and Health Surveys (DHS) of Ethiopia and other African countries. Second, hand search (manual search) for local articles that are not available electronically in full document was conducted in the College of Health Sciences library, Addis Ababa University.

The community based small scale studies included (14-17), national representative surveys (9-11), and hospital based studies (18-24) estimated the 
maternal mortality by applying an indirect sisterhood method $(25,26)$, and by reviewing medical records in the specific study hospitals, respectively. To be more specific, in the indirect sisterhood method, the respondents reported the proportion of their adult sisters who died during pregnancy, childbirth, or within 6 weeks following pregnancy, which was a kind of retrospective cohort method to estimate the chance of a woman dying from pregnancy-related causes during her entire reproductive period (26).

The Institute for Health Metrics and Evaluation produced a maternal mortality estimated for 181 countries for 1980-2008 using vital registration data, census, surveys, and verbal autopsy studies. The four UN agencies (WHO, UNICEF, UNFPA and The World Bank) also jointly estimated the maternal mortality for 180 countries for 1990-2010 using almost similar data. In all Ethiopian demographic and health surveys (EDHS), estimation of maternal mortality was done for the seven-year period preceding each survey (the 2000 EDHS for the year 1993-2000, the 2005 EDHS for the year 1998-2005, and the 2011 EDHS for the year 2004-2011). The results of this review are presented in the form of line and stock graphs.

\section{RESULTS}

In this analysis, 18 studies (3 nationally representative surveys, 2 secondary data analysis, 5 small scale community based studies, and 8 hospital based studies) were included (Table 1). Historically, small scale community based maternal mortality estimates were done starting from the early 1980s (14-17). The first hospital based maternal mortality ratio (804 per 100,000 live births) estimation was done by Frost $\mathrm{O}$ in Addis Ababa in 1980 (18). Similarly, the first community based maternal mortality ratio was estimated for Addis Ababa in 1981-1983 by Kwast et al (19).

Figure 1 shows the mean maternal mortality ratio (MMR) trend for the nation as estimated by the three EDHSs $(2000,2005,2011)$ (9-11), WHO (3, 4) and by the Institute for Health Metrics and Evaluation (2). The mean MMR estimates in both WHO et al and Hogan et al data demonstrated a continuous down-going trend. The WHO et al MMR estimation for 2010 in particular was nearly half of the EDHS 2011 estimate (350 vs 676), and it is the ever lowest MMR estimate for the nation. However, it should be noted that in another report (27), WHO MMR estimation for the year 2006 (850/100,000 live births) was even higher than the estimation for the year $2000(700 / 100,000$ live births) (3). 
Table 1: General characteristics of the included data sources

\begin{tabular}{|c|c|c|c|c|}
\hline Authors & $\begin{array}{l}\text { Year study } \\
\text { done/reported }\end{array}$ & $\begin{array}{l}\text { Study } \\
\text { period }\end{array}$ & Study design & Setting \\
\hline Hogan MC et al (1) & 2010 & $1980-2008$ & $\begin{array}{l}\text { Secondary data } \\
\text { analysis }\end{array}$ & $\begin{array}{l}\text { Vital registration data, censuses, } \\
\text { surveys, and verbal autopsy } \\
\text { studies }\end{array}$ \\
\hline $\begin{array}{ll}\text { World } & \text { Health } \\
\text { organization (3) } & \end{array}$ & 2012 & $1990-2010$ & $\begin{array}{l}\text { Secondary data } \\
\text { analysis }\end{array}$ & $\begin{array}{l}\text { Databases, } \quad \text { DHS, } \\
\text { registration, GDP, GFR, SAB }\end{array}$ \\
\hline $\begin{array}{l}\text { The Central Statistics } \\
\text { Agency/ORC Macro (10) }\end{array}$ & 2000 & $1993-2000$ & $\begin{array}{l}\text { Indirect } \\
\text { sisterhood } \\
\text { method }\end{array}$ & $\begin{array}{l}\text { Community based -household } \\
\text { survey }\end{array}$ \\
\hline $\begin{array}{lr}\text { Central } & \text { Statistics } \\
\text { Agency/ORC Macro (11) }\end{array}$ & 2005 & $1998-2005$ & $\begin{array}{l}\text { Indirect } \\
\text { sisterhood } \\
\text { method } \\
\end{array}$ & $\begin{array}{l}\text { Community based -household } \\
\text { survey }\end{array}$ \\
\hline $\begin{array}{lr}\text { Central } & \text { Statistics } \\
\text { Agency/ORC Macro (12) }\end{array}$ & 2011 & 2004-2011 & $\begin{array}{l}\text { Indirect } \\
\text { sisterhood } \\
\text { method } \\
\end{array}$ & $\begin{array}{l}\text { Community based -household } \\
\text { survey }\end{array}$ \\
\hline Yaya Y et al (13) & 2012 & 1998 & $\begin{array}{l}\text { Idirect } \\
\text { sisterhood } \\
\text { method }\end{array}$ & $\begin{array}{lll}\text { Community } & \text { based } & \text { - Verbal } \\
\text { autopsy } & & \end{array}$ \\
\hline Shiferaw T et al (14) & 1993 & 1991 & $\begin{array}{l}\text { Indirect } \\
\text { sisterhood } \\
\text { method } \\
\end{array}$ & $\begin{array}{l}\text { Community based - Verbal } \\
\text { autopsy }\end{array}$ \\
\hline $\begin{array}{l}\text { Berhane Y et al (study 2) } \\
\text { (15) }\end{array}$ & 2000 & $1987-1999$ & $\begin{array}{l}\text { Indirect } \\
\text { sisterhood } \\
\text { method } \\
\end{array}$ & $\begin{array}{l}\text { Community based - Verbal } \\
\text { autopsy }\end{array}$ \\
\hline $\begin{array}{l}\text { Berhane Y et al (study 2) } \\
\text { (16) }\end{array}$ & 1999 & $1987-1996$ & $\begin{array}{l}\text { Indirect } \\
\text { sisterhood } \\
\text { method }\end{array}$ & $\begin{array}{l}\text { Community based - Verbal } \\
\text { autopsy }\end{array}$ \\
\hline Frost O (17) & 1984 & 1980 & $\begin{array}{l}\text { Medical chart } \\
\text { review }\end{array}$ & $\begin{array}{l}\text { Hospital based - Medical } \\
\text { records }\end{array}$ \\
\hline Kwast BE et al (18) & 1985 & 1981-1983 & $\begin{array}{l}\text { Verbal autopsy } \\
\text { and medical } \\
\text { chart review }\end{array}$ & $\begin{array}{l}\text { Community \& hospital based - } \\
\text { Verbal autopsy and medical } \\
\text { records }\end{array}$ \\
\hline Yoseph S et al (19) & 1988 & $1980-1985$ & $\begin{array}{l}\text { Medical chart } \\
\text { review }\end{array}$ & $\begin{array}{l}\text { Hospital based - Medical } \\
\text { records }\end{array}$ \\
\hline Gaym A (20) & 2000 & 1990-1999 & $\begin{array}{l}\text { Medical chart } \\
\text { review }\end{array}$ & $\begin{array}{l}\text { Hospital based - Medical } \\
\text { records }\end{array}$ \\
\hline Mezgebu A et al (21) & $\begin{array}{l}\text { Unpublished } \\
\text { specialty } \\
\text { thesis }\end{array}$ & 1995-1998 & $\begin{array}{l}\text { Medical chart } \\
\text { review }\end{array}$ & $\begin{array}{l}\text { Hospital based - Medical } \\
\text { records }\end{array}$ \\
\hline Garomsa H et al (22) & 2008 & $2001-2005$ & $\begin{array}{l}\text { Medical chart } \\
\text { review }\end{array}$ & $\begin{array}{l}\text { Hospital based - Medical } \\
\text { records }\end{array}$ \\
\hline Kelly J et al (23) & 2010 & $1987-2008$ & $\begin{array}{l}\text { Medical chart } \\
\text { review }\end{array}$ & $\begin{array}{l}\text { Hospital based - Medical } \\
\text { records }\end{array}$ \\
\hline Hill K et al (27) & 2001 & 1995 & $\begin{array}{l}\text { Indirect } \\
\text { sisterhood } \\
\text { method }\end{array}$ & $\begin{array}{l}\text { Community based - Verbal } \\
\text { autopsy }\end{array}$ \\
\hline
\end{tabular}

GDP $=$ gross domestic product per capita; GFR $=$ gross fertility rate; SBA $=$ skilled attendant at birth 


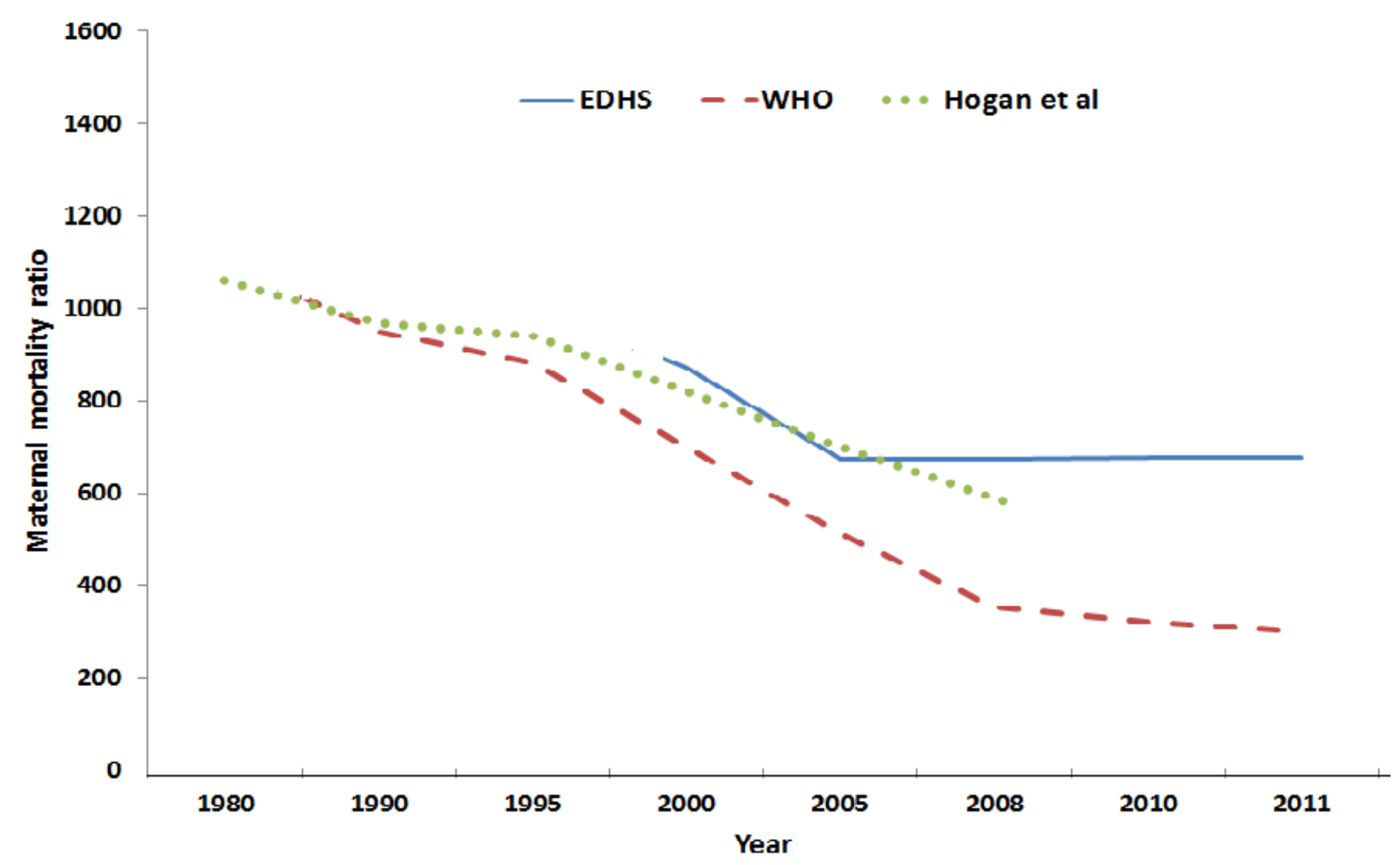

Figure 1: The trend of the national maternal mortality ratio as estimated by the Ethiopian demographic and health surveys (EDHS) (10-12), World Health Organization (WHO) (2, 3) and Hogan et al (1)

The MMRs reported from the small scale community-based studies also showed significant variation. According to Hill and colleagues' estimation, in 1995, the MMR of Ethiopia was 1814 per 100,000 live births (28), which was very close to the finding of Yaya Y et al's study (1667 per 100,000 live births) for the year 1998 (14). However, the other small scale community based studies reported relatively lower MMRs. In 1982/83, for Addis Ababa 566 (19); in 1991, for Illubabor 570 (95\% CI, 420-720) (15); in 19871994 and 1987-1996, for Butajira 665 (95\% CI, 558-785) and 512 (95\% CI, 440-665) (16, 17), respectively, were 2-3 fold less than the other two reports $(14,28)$.

Figure 2 shows the trend of MMR as estimated from hospital based and small scale community based studies (14-24, 28). Unlike the national estimates, the MMRs showed an overall increasing trend in both hospital and community based studies. Although there were some overlaps with MMR estimates in the 1990s and early 2000s, the overall MMRs reported from hospital based studies were higher than the community based studies. 


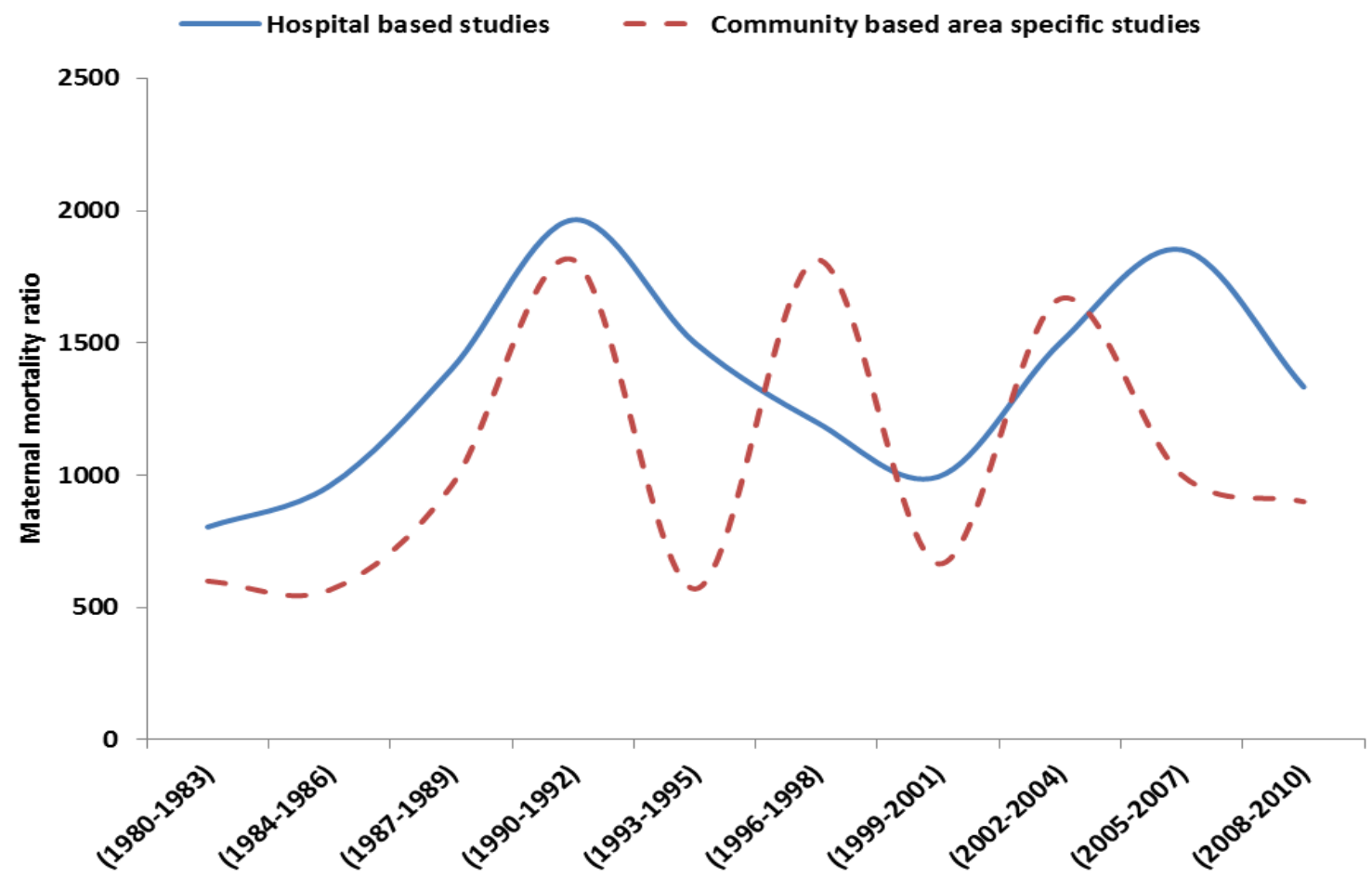

Figure 2: The trend of maternal mortality ratio in Ethiopia (1980-2010) as estimated from community based small scale studies (13-16) and hospital based studies (17-23)

In a closer assessment, neither the national nor the small scale studies' estimates demonstrated a significant change in MMR over the last three decades. To be more specific, in the Hogan et al (2) estimates (Figure 3), the MMR dropped from 1061 in 1980 to 590 per 100,000 live births in 2008. However, the MMR confidence intervals in the 1990 and 2000 were almost in the same line with the 1980 MMR confidence interval. The upper bound confidence interval for the 2008 MMR was almost equivalent to the three preceding MMR estimates. In short, because the confidence intervals among the four estimates overlapped, there was no evidence that demonstrated a change in MMR in the past 30 years (1980-2008).

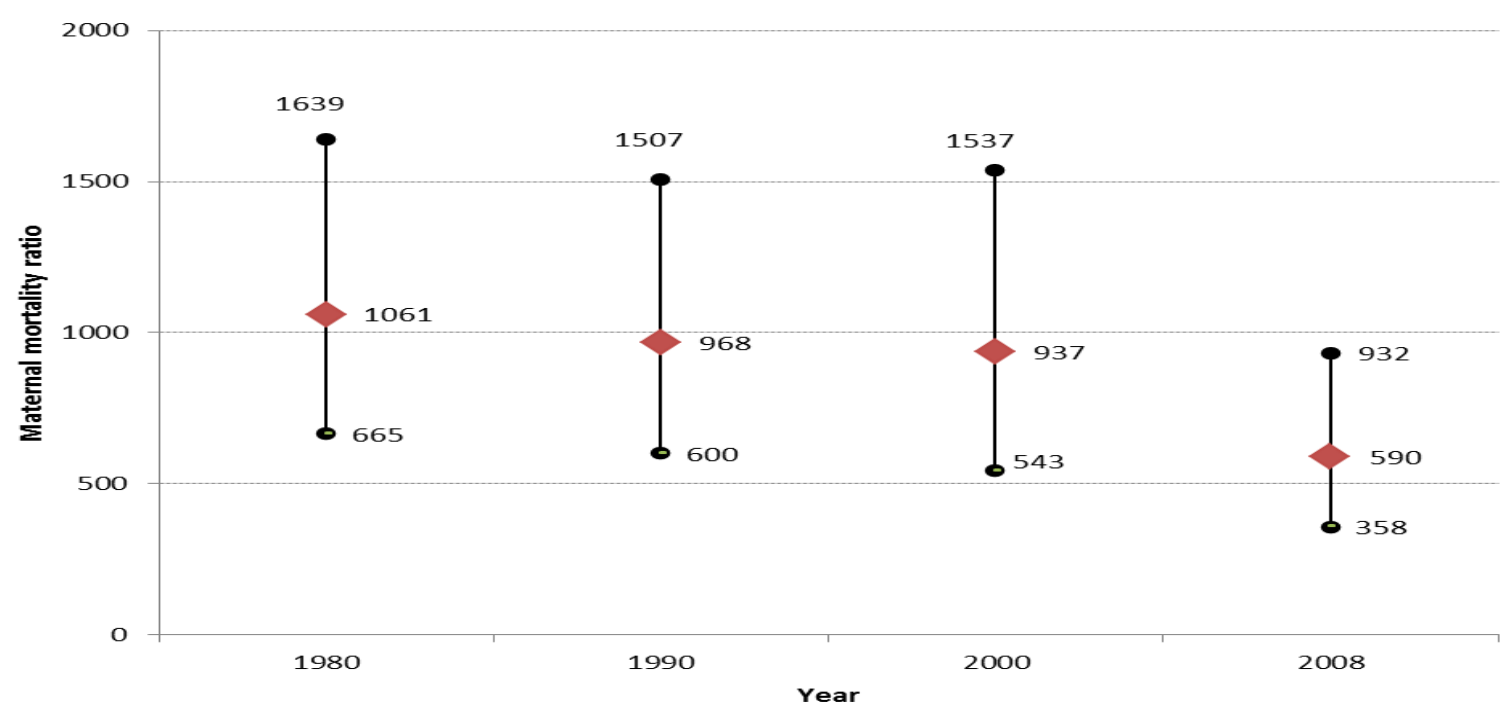

Figure 3: The trend of the Ethiopian maternal mortality ratio with 95\% confidence interval from Hogan et al estimation (1) 
A similar conclusion can be drawn for the three demographic and health surveys of Ethiopia (Figure 4). The MMR confidence intervals for the 1995-2011 estimates showed significant, another evidence that supports the lack of significant reduction in MMR during the three survey periods. As shown in Fig 5, the MMR (with the
95\% confidence interval upper bound) between 1987 and 1996 was almost similar to Frost O's (18) estimate for the 1980. However, the 1998 MMR estimate by Yaliso Y et al was nearly twice of the 1987-1996 estimates (14 - 17) but close to Hill K et al (28) estimate for the year 1995.

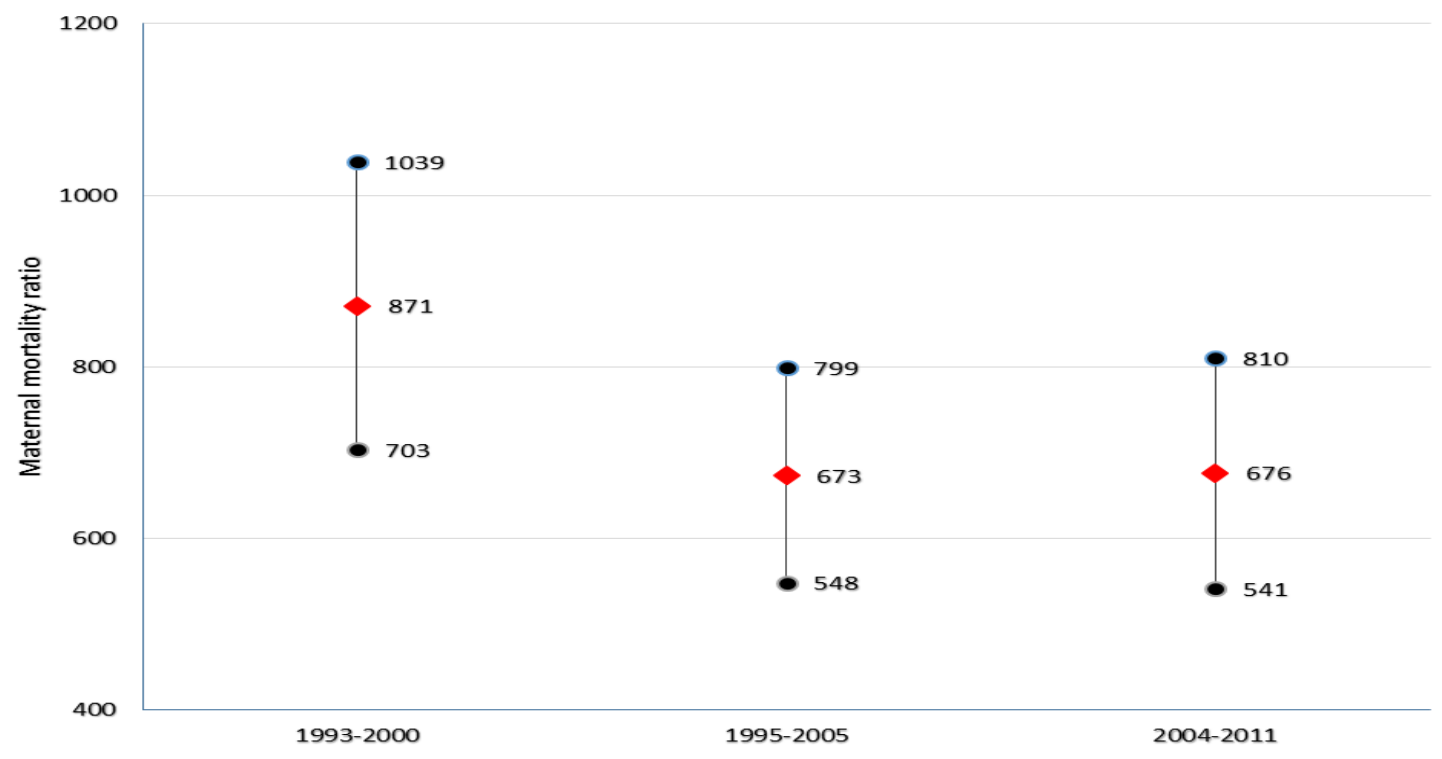

Figure 4: The trend of maternal mortality ratio with $95 \%$ confidence interval as estimated by the EDHS for year 1993 - 2000, 1998-2005 and 2004-2011 (Adapted from EDHS 2011)

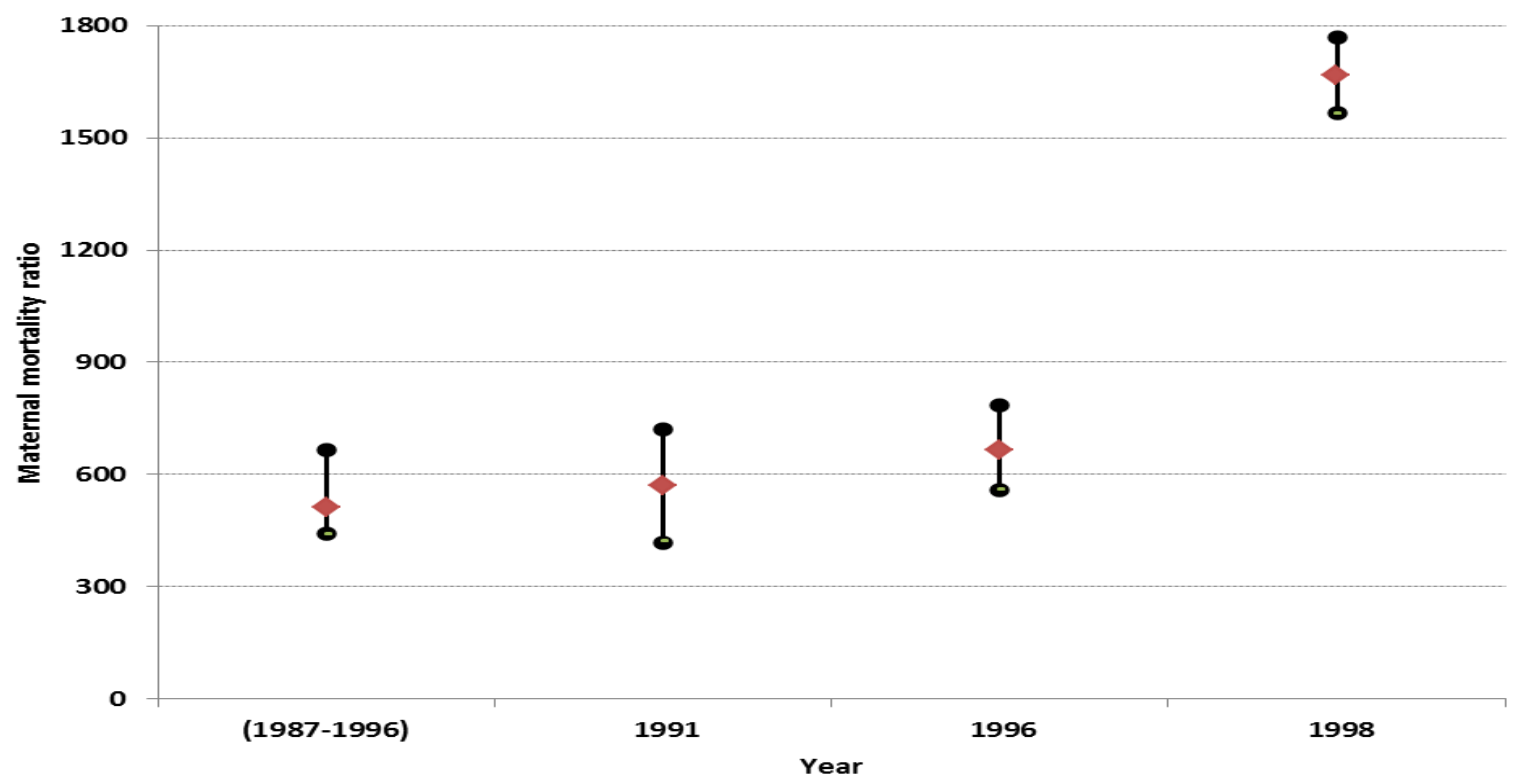

Figure 5: The trend of maternal mortality ratio with $95 \%$ confidence interval as estimated from community based studies (13-16) 
Marked variation in MMR was also observed among hospital based studies (20-24) (Figure 6). The MMR report from one of the hospitals in Addis Ababa for 1980-1985 was significantly lower than the report from Jimma Hospital for 1990-1999 but very comparable with Mezgebu et al report in the same city for 1995-1998. Although there was a very wide confidence interval, the MMR report from Jimma Hospital in South West Ethiopia was comparable with the MMR report from Ambo Hospital in central Western Ethiopia for 2001-2005.

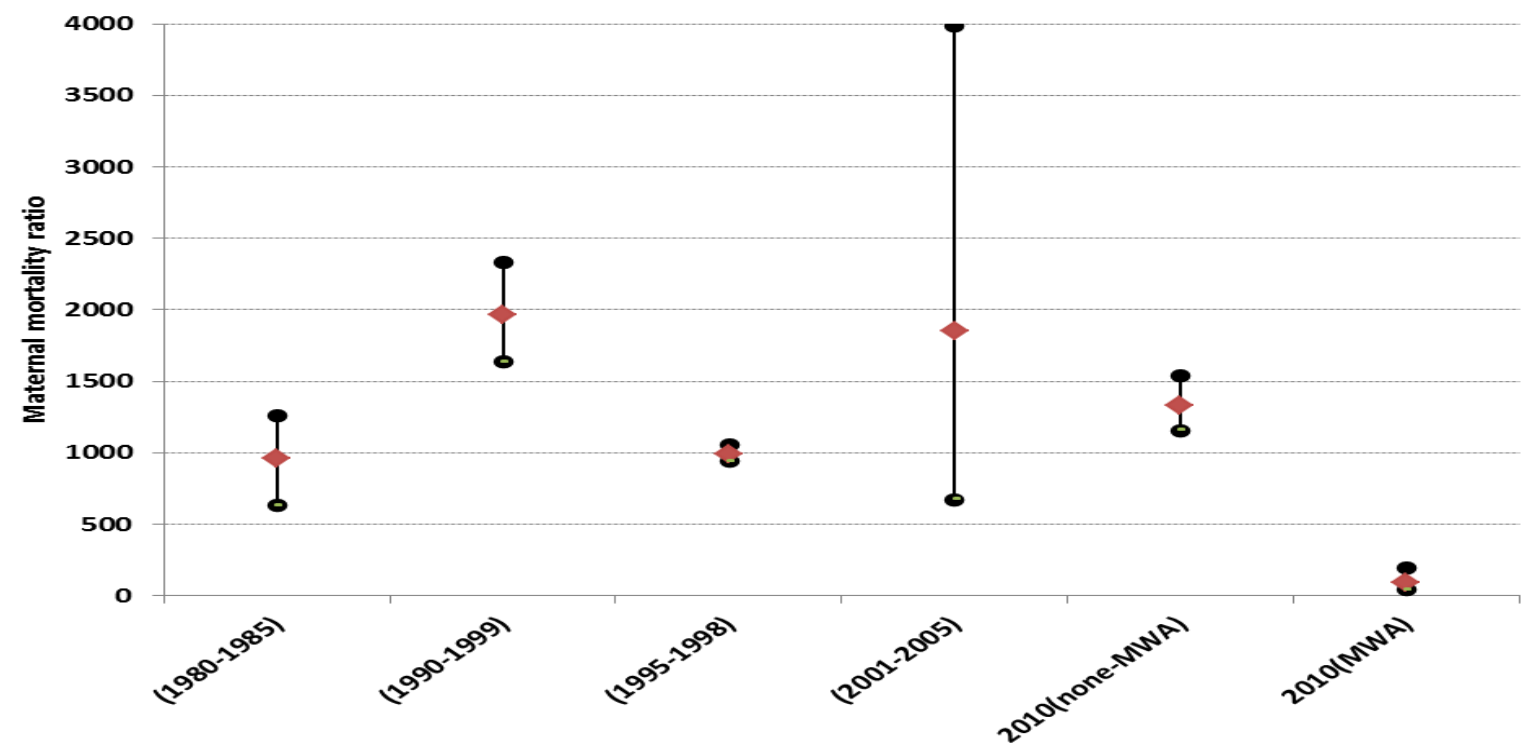

MWA = Maternity waiting area

Figure 6: The trend of maternal mortality ratio with $95 \%$ confidence interval as reported from hospital based studies $(21-25)$

The report from Atat Hospital in Central South Ethiopia for 1987-2008 is the only evidence that demonstrated a very significant drop in MMR among mothers who were kept in the maternity waiting area (MWA) ahead of the date of delivery. In this study, out of 24,148 deliveries over the study period, 6805 were admitted via MWA and 17,343 were admitted on emergency base. Interestingly, while the MMR for the MWA group was 90 per 100,000 live births (95\%CI 41-195), the MMR for the non-MWA group was 1333
(95\%CI 1156-1537), which was nearly 15 -fold of the MMR of the group in the MWA.

In general, although there were marked variations in the 95\% CI among individual studies, both the community based and hospital based studies demonstrated that there was no significant change in MMR in about 30 years period (19802010). The 2011 EDHS has also shown that maternal deaths were $30 \%$ of all deaths in women age 15-49 years, which was higher than 2005 (21\%) and 2000 EDHS (25\%). 


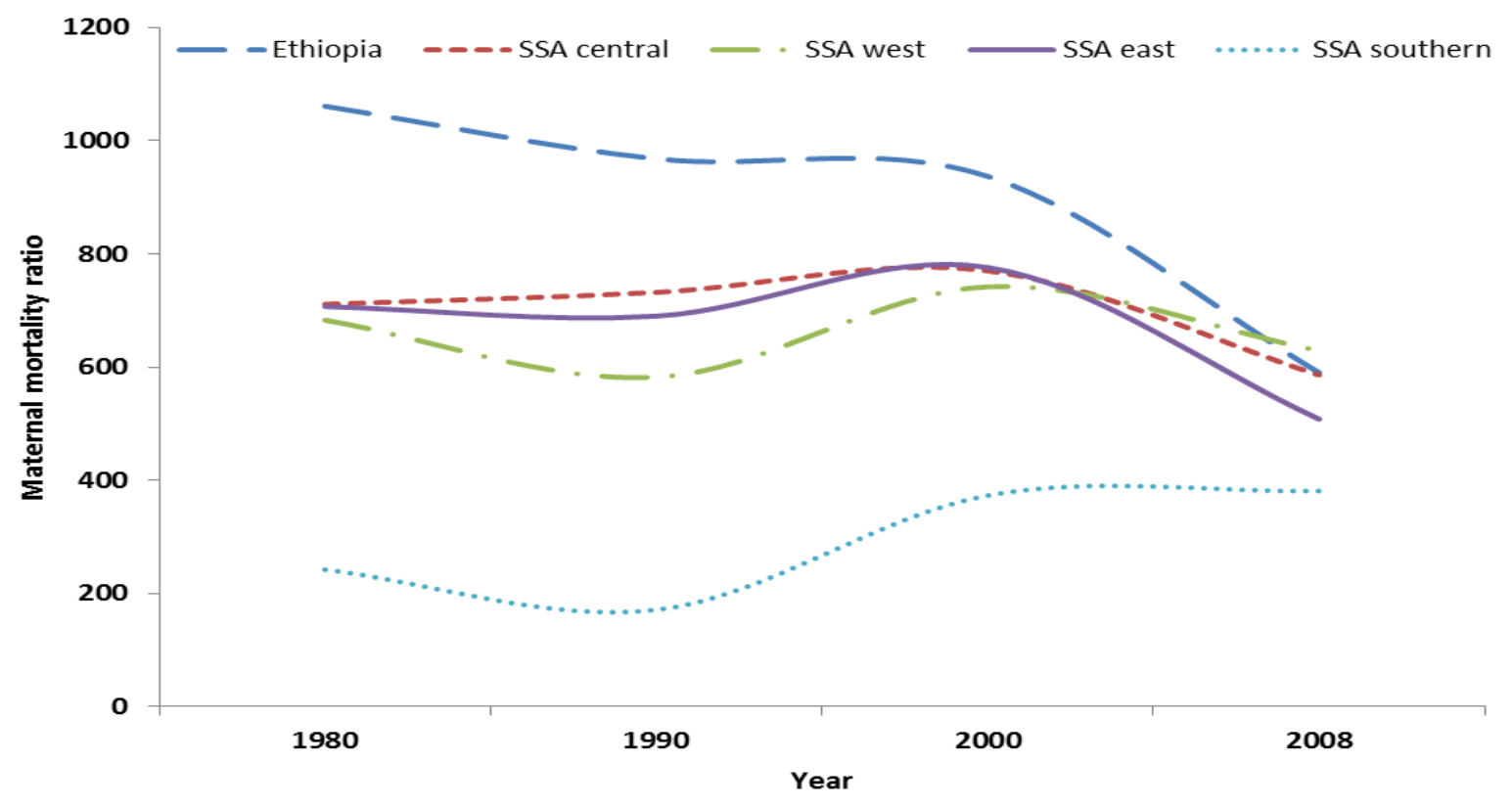

Figure 7: The trend of the mean maternal mortality ratio (MMR) estimates for Sub-Saharan African (SSA) countries by zone in comparison with the trend of Ethiopian MMR (1)

\section{DISCUSSION}

Both the community based and hospital based studies have shown that there was no significant changes in maternal mortality in about thirty years' period. Several SSA countries have also experienced either persistence or a surge in the MMR between 1990 and 2000, for which high HIV prevalence in that period was attributed (29). The only report that showed a marked drop in maternal mortality in Ethiopia was the intervention implemented in Atat Hospital over a 22-year period (keeping pregnant women identified as high-risk in maternity waiting area). This is probably one of the strongest evidences that support the importance of identifying pregnant women with risk during antenatal care and linking them with a health facility delivery. Other studies also reported a significant reduction in perinatal and maternal mortality among mothers kept in the maternity waiting area (30-32).

The challenge with keeping high-risk mothers to a maternity waiting area, however, is beyond the resource issue; the majorities of the causes of maternal mortality is unpredictable during antenatal care and usually occur during and immediately after delivery $(33,34)$. This raises a challenging question to the Atat study.

How many of the pregnant women who were identified as low risk during antenatal care (who were not offered waiting in the maternity center) actually developed complications during and after delivery? The answer to this question is unknown until proven. An evidence supporting this argument was reported by the Kasongo project team in Zaire in 1984; $71 \%$ of the women who developed obstructed labor were not categorized as "high risk" during antenatal care, while $90 \%$ of women who were identified as "high risk" did not develop obstructed labor (35).

Although the trend in the overall maternal mortality remains high and stable over three decades, there were several inconsistencies in both the community based and hospital based studies. The variation among hospital based studies may be explained by the fact that stating that reports coming from different areas/setting with different socioeconomic background of the population included as study participants are likely to vary; and also because of differences in their study period (36). 
Among community based studies, there were also marked variations in MMR estimates even in the same period. The MMR of Ethiopia estimated by WHO and other UN agencies (3) for the year 2010 was nearly half of the EDHS 2011 estimate (350 vs 676). This is probably due to the fact that maternal mortality is difficult to measure accurately. It was noted that large sample sizes are required to increase the accuracy of maternal mortality estimation (12). In other words, since the actual number of maternal deaths is very few in a given community or at the national level, it requires a large sample size, which is very costly and time consuming to undertake. As a result, it should be noted that the community based MMR estimates included in this review were subject to large sampling errors - the actual MMR of Ethiopia may be under- or over-estimated in both nationally representative and small scale community based surveys.

In an ideal setting, accurate data on the magnitude of maternal mortality is provided by instituting civil registration across the country. Otherwise, as WHO and other UN agencies (3) pointed out, the levels of maternal mortality may not be accurate due to several reasons: lack of medical certification of cause of maternal death in developing countries; the maternal death may not be recorded at all in health facilities; and cause of a woman's death may not be recorded as maternal death.

The community based studies included in this review applied a household survey (sisterhood method) which has several limitations (3): pregnancy-related deaths are identified instead of maternal deaths; the maternal mortality is estimated with wide confidence intervals; the data set is retrospective ( 5 years prior to the survey); and the analysis is said to be more complicated. Similarly, The Institute for Health Metrics and Evaluation (2), the WHO and other UN agencies (3) estimated the MMR also using the previous national surveys (probably the EDHS 2000 and 2005), the proportion of AIDS deaths, the gross domestic product (GDP), the general fertility rate (GFR) and the SAB, which all are likely to widen the $95 \%$ confidence interval of maternal mortality estimation and compromise the accuracy of estimation.

WHO and other UN agencies estimated the MMR of Ethiopia for 2010 to be about half of the
EDHS 2011 probably due to the marked drop in HIV related mortality after the year 2005 for which the widely used antiretroviral therapy was credited. Secondly, since the WHO MMR estimation for its member countries partly take their DHS data into consideration, we surmise that the estimation could have been closer to the EDHS 2011 if WHO has got the chance to include the EDHS 2011 MMR report.

When the Ethiopian MMR trend is compared with that of Sub-Saharan African MMRs, in the majority of the countries similar trend is observed, of course with variable magnitude $(2,3)$. As shown in Figure 7, the MMR estimate for Ethiopia was above the mean for any of the Sub-Saharan African (SSA) zones with the exception of the estimate for 2008, in which the MMR estimated for Ethiopia was almost equal with the mean MMR estimated for SSA countries by zone. However, when the MMRs of Ethiopia is compared with other individual countries, it was lower than the estimates for Chad (1100), Somalia (1000), Sierra Leone (890), the Central African Republic (890), Burundi (800), Guinea-Bissau (790), Liberia (770), Sudan (730), Cameroon (690) and Nigeria (630) per 100,000 live births.

In general, although several SSA countries experienced a surge in the MMR between 1990 and 2000, for which high HIV prevalence was incriminated, there has been an ongoing but an insignificant decline in MMR in Ethiopia between 1980 and 2011. Although the available data have shown that the MMR in Ethiopia has remained virtually unchanged in the last three decades, there are limitations to this observation. Among others, because of the very difficult nature of MMR estimation by design, the actual MMR of Ethiopia during the study period might be under-or overestimated by the authors of the studies included in this review.

In conclusion, although MDG and HSDP IV Ethiopia envisaged significant improvement in maternal health by this time, this review has shown that the performances are still far from the target. Therefore, to achieve the MDG5 at least before 2025 and the HSDPIV target during HSDP V-VII period, multisectoral commitment and huge investment are required. 


\section{ACKNOWLEDGEMENT}

We would like to thank PANE and KMG Ethiopia for the modest financial support granted for this review. We are also grateful to UNFPA Ethiopia for their generous financial support to cover the publication fee.

\section{REFERENCES}

1. World Health Organization (WHO), World Health Report 2005: Make Every Mother and Child Count (Geneva: WHO, 2005). www.who.int/whr/2005/whr2005_en.pdf

2. Hogan MC, Foreman KJ, Naghavi M, et al. Maternal mortality for 181 countries, 1980 2008: a systematic analysis of progress towards Millennium Development Goal 5. The Institute of Health Metrics and Evaluation (IHME) at the University of Washington in Seattle, USA. Lancet 2010; 375: 1609-23

3. World health organization. World Health Statistics 2013. Last accessed in August 2013: www.who.int/entity/gho/.../world_health_stati stics/EN_WHS2013_Full.pdf

4. WHO, UNICEF, UNFPA and The World Bank estimates.trends in Maternal Mortality: 1990 to 2010 Retrieved from: http://whqlibdoc.who.int/publications/2012/97 89241503631_eng.pdf

5. WHO, UNFPA, UNICEF, and Averting Maternal Death and Disability (AMDD). Monitoring emergency obstetric care. A handbook. WHO 2009.

6. Federal Democratic Republic of Ethiopia Ministry of Health. Health Sector Development Programme IV. FMOH, 2010.

7. Federal Democratic Republic of Ethiopia Ministry of Health. National reproductive health strategy 2006-2015. FMOH, 2006.

8. Koblinsky M, Tain F, Gaym A, et al. Responding to the maternal health care challenge: The Ethiopian Health Extension Program. Ethiop J Health Dev 2010; 24 (Special Issue 1): 105-109.

9. Central Statistical Agency [Ethiopia] and ICF International. 2001. Ethiopia Demographic and Health Survey 2000. Addis Ababa, Ethiopia and Calverton, Maryland, USA: Central Statistical Agency and ICF International.
10. Central Statistical Agency [Ethiopia] and ICF International. 2006. Ethiopia Demographic and Health Survey 2005. Addis Ababa, Ethiopia and Calverton, Maryland, USA: Central Statistical Agency and ICF International.

11. Central Statistical Agency [Ethiopia] and ICF International. 2012. Ethiopia Demographic and Health Survey 2011. Addis Ababa, Ethiopia and Calverton, Maryland, USA: Central Statistical Agency and ICF International.

12. Abdella A. Maternal Mortality Trend in Ethiopia. Ethiop J Health Dev 2010; 24 (Special Issue 1):115-122.

13. Gaym A. Maternal mortality studies in Ethiopia-magnitude, causes and trends. Ethiop Med J 2009; 47(2): 95-108.

14. Yaya Y, Lindtjørn B. High maternal mortality in rural south-west Ethiopia: estimate by using the sisterhood method BMC Pregnancy and Childbirth 2012; 12:136 http://www.biomedcentral.com/14712393/12/136

15. Shiferaw T, Tessema F. Maternal mortality in rural communities of Illubabor, southwestern Ethiopia: as estimated by the sisterhood method. Ethiop Med J 1993; 31(4):239-249.

16. Berhane Y, Andersson T, Wall S, Byass P, Hogberg U. Aims, options and outcomes in measuring maternal mortality in developing societies. Acta Obstet Gynecol Scand 2000; 79(11):968-972. (Study 2)

17. Berhane Y, Wall S, Kebede D, et al. Establishing an epidemiological field laboratory in rural areas - potentials for public health research and interventions: The Butajira Rural Health Programme 1987-1999. Ethiop J Health Dev 1999; 13: 30-32. (Study 1)

18. Frost O. Maternal and perinatal death in an Addis Ababa hospital. Ethiop Med J 1984; 35:114-8.

19. Kwast BE, Rochat RW, Kidane-Mariam W. Maternal Mortality in Addis Ababa, Ethiopia. Stud Fam Plann 1986; 17(6):288-301.

20. Yoseph S and Kifle G. A six year review of maternal mortality in a teaching hospital in Addis Ababa. Ethiop Med J 1988; 26:115119. 
21. Gaym A. A review of maternal mortality at Jimma hospital, South West Ethiopia. Ethiop J Health Dev 2000; 14(2):215-223.

22. Mezgebu A. A three year review of maternal mortality at two teaching hospitals in Addis Ababa. (Unpublished specialty thesis).

23. Garomsa H, Dwividi AD. Maternal mortality in Ambo hospital: A five year retrospective review. Ethiop J Reprod Health 2008; 2: 2-13.

24. Kelly J, Kohls E, Poovan P, et al. The role of a maternity waiting area (MWA) in reducing maternal mortality and stillbirths in high-risk women in rural Ethiopia. BJOG 2010;117:1377-1383.

25. Graham W, Brass W, Snow RW. Indirect Estimation of Maternal Mortality: The Sisterhood Method. Studies in Family Planning 1989; 20(3): 125-135.

26. Rutenberg N, Sullivan J. Direct and Indirect Estimates of Maternal Mortality from the Sisterhood Method. In: Proceedings of the Demographic and Health Surveys World Conference, Columbia, Maryland: IRD/Macro International Inc.1991; 3: 1669-1696.

27. The World Bank, Data and Statistcs: Ethiopia, 2009 retrieved from: http://web.worldbank.org/wbsite/external/cou ntries/Africa/ext/Ethiopia, 2009.

28. Hill K, AbouZahr C, Wardlaw T. Estimates of maternal mortality for 1995. Bull World Health Organ 2001, 79:182-193.

29. WHO, UNICEF and UNAIDS. Global HIV/AIDS response: epidemic update and health sector progress towards universal access progress report 2011. Geneva, World Health Organization, 2011 (http://whqlibdoc.who. int/publications/2011/.

30. Tumwine JK, Dungare PS. Maternity waiting shelters and pregnancy outcome: experience from a rural area in Zimbabwe. Ann Trop Paediatr 1996;16(1):55-9.

31. Chandramohan D, Cutts F and Millard P. The effect of stay in a maternity waiting home on perinatal mortality in rural Zimbabwe.

Trop Med Hyg 1995; 98(4):261-7.

32. Gaym A, Pearson L, Soe KW. Maternity waiting homes in Ethiopia--three decades experience. Ethiop Med J 2012; 50(3):209-19.

33. Rogo KO, Oucho J, Mwalali P. Maternal Mortality. In: Jamison DT, Feachem RG, Makgoba MW, et al., editors. Disease and
Mortality in Sub-Saharan Africa. 2nd edition. Washington (DC): World Bank; 2006. Chapter 16. Available from: http://www.ncbi.nlm.nih.gov/books/NBK2288

34. Miller S, Sloan N, Winikoff B, Langer A, Fikree F. Where is the ' $\mathrm{E}$ ' in $\mathrm{MCH}$ ? The need for an evidence-based approach in safe motherhood. J Midwifery Women's Health 2003;48:10-8.

35. Heat program, Open University/London. Antenatal care, blended learning module for the Health Extension workers. Last accessed in August 2013. labspace.open.ac.uk/course/view

36. 30. Mortensen LH, Helweg-Larsen K, Andersen A-M N. Socioeconomic differences in perinatal health and disease. Scand J Public Health 2011; 39(Suppl 7): 110-114. 